\title{
Estimation of aerosol complex refractive indices for both fine and coarse modes simultaneously based on AERONET remote sensing products
}

\author{
Ying Zhang ${ }^{1}$, Zhengqiang $\mathrm{Li}^{1}$, Yuhuan Zhang ${ }^{2}$, Donghui $\mathrm{Li}^{1}$, Lili Qie ${ }^{1}$, Huizheng Che ${ }^{3}$, and Hua Xu${ }^{1}$ \\ ${ }^{1}$ State Environmental Protection Key Laboratory of Satellite Remote Sensing, Institute of Remote Sensing and Digital Earth, \\ Chinese Academy of Sciences, Beijing 100101, China \\ ${ }^{2}$ Satellite Environment Center, Ministry of Environmental Protection, Beijing 100094, China \\ ${ }^{3}$ Chinese Academy of Meteorological Sciences, Chinese Meteorological Administration, Beijing 100081, China
}

Correspondence to: Zhengqiang Li (lizq@radi.ac.cn)

Received: 6 January 2017 - Discussion started: 31 March 2017

Revised: 4 July 2017 - Accepted: 2 August 2017 - Published: 1 September 2017

\begin{abstract}
Climate change assessment, especially model evaluation, requires a better understanding of complex refractive indices (CRIs) of atmospheric aerosols - separately for both fine and coarse modes. However, the widely used aerosol CRI obtained by the global Aerosol Robotic Network (AERONET) corresponds to total-column aerosol particles without separation for fine and coarse modes. This paper establishes a method to separate CRIs of fine and coarse particles based on AERONET volume particle size distribution (VPSD), aerosol optical depth (AOD) and absorbing AOD (AAOD). The method consists of two steps. First a multimodal log-normal distribution that best approximates the AERONET VPSD is found. Then the fine and coarse mode CRIs are found by iterative fitting of AERONET AODs to Mie calculations. The numerical experiment shows good performance for typical water-soluble, biomass burning and dust aerosol types, and the estimated uncertainties on the retrieved sub-mode CRIs are about 0.11 (real part) and $78 \%$ (imaginary part). The 1-year measurements at the AERONET Beijing site are processed, and we obtain CRIs of 1.48-0.010i (imaginary part at $440 \mathrm{~nm}$ is 0.012 ) for fine mode particles and 1.49-0.004i (imaginary part at $440 \mathrm{~nm}$ is 0.007 ) for coarse mode particles, for the period of 20142015. Our results also suggest that both fine and coarse aerosol mode CRIs have distinct seasonal characteristics; in particular, CRIs of fine particles in winter season are significantly higher than summer due to possible anthropogenic influences.
\end{abstract}

\section{Introduction}

Complex refractive indices (CRIs) of aerosols, describing scattering and absorption properties of atmospheric particulate matters, are important parameters affecting calculation of the shortwave radiative budget and aerosol climate effect. Improving the knowledge of aerosol CRIs is of great interests to decrease the uncertainties associated with aerosols in the climate change assessment (Boucher et al., 2013). Since the 20th century, direct measurement approaches of CRIs of small particles have been developed in the laboratory (e.g., Woo et al., 2013; Mogo et al., 2012; Marley et al., 2001; Patterson et al., 1977; Volz, 1973). As to aerosol particles in the real atmosphere, many studies retrieved CRIs of nearground-surface aerosols (e.g., Kostenidou et al., 2007; Malloy et al., 2009; Dinar et al., 2006; McMurry et al., 2002) through in situ measurements of particle size distribution as well as scattering and absorption coefficients. Meanwhile, several remote sensing methods were developed to obtain CRIs of total-column atmospheric aerosols (e.g., Raut and Chazette, 2007; Li et al., 2006; Sinyuk et al., 2003; Dubovik and King, 2000; Kaufman et al., 2001; Wendisch and von Hoyningen-Huene, 1994; Nakajima et al., 1983). As Nakajima et al. (1983) and Wendisch and von Hoyningen-Huene (1994) reported, the aerosol CRIs can be retrieved by using spectral aerosol optical depth (AOD) and diffusely scattered radiances. One of widely recognized CRI remote sensing approaches is the statistically optimal estimation method based on Sun-sky-radiometer measurements (Dubovik and 
King, 2000), which has been successfully implemented in the worldwide Aerosol Robotic Network (AERONET; Holben et al., 1998, 2001). In addition, Li et al. (2006) further added the polarized sky radiance measurements to the inversion algorithm in order to better constrain AERONET CRI retrievals. The lidar measurements are also used to obtain CRIs of aerosols within the planetary boundary layer (Raut and Chazette, 2007).

Although the above-mentioned remote sensing methods retrieve CRIs of total-column aerosols, it still remains a big challenge to obtain CRIs simultaneously for different modes (e.g., fine and coarse modes). CRIs of fine and coarse modes may differ significantly due to different compositions and sources (Marley et al., 2001). For example, fine modes are mainly determined by anthropogenic emission or nucleation processes, while coarse modes are dominated by natural sources of windblown dust or sea salt (Willeke and Whitby, 1975). As to atmospheric models, e.g., the global three-dimensional chemical transport model (GEOS-Chem) and the Community Multiscale Air Quality model, aerosols radiative properties are simulated based on source emission inventories (i.e., fine and coarse sources separately), and thus knowledge of CRIs of different aerosol modes is essential to validate model performance for the assessment of aerosol climate effects. Only a few studies (e.g., Xu et al., 2015; Wu et al., 2015) have attempted to retrieve CRIs of both fine and coarse modes simultaneously from advanced remote sensing measurements, e.g., multispectral polarized sky radiance. Meanwhile, most AERONET sites provide official CRI products without distinguishing fine and coarse modes. Considering the essential values of worldwide, long-term continuous and high-quality AERONET CRI datasets, the development of an approach to separate CRIs for both fine and coarse modes is valuable, based directly on AERONET official aerosol products, instead of developing an entire algorithm performing retrievals from radiance level.

In this paper, we introduce a method to separate the CRI of both fine and coarse modes from AERONET aerosol products (Sect. 2). Section 3 presents the theoretical simulation and analyses and Sect. 4 focuses on the results of 1-year measurements in Beijing. The results are summarized in Sect. 5 .

\section{Method}

The ground-based Sun-sky radiometer is one of the major instruments observing total-column atmospheric aerosol properties. There are several long-term Sun-sky-radiometer networks operated regionally or globally, e.g., AERONET (Holben et al., 1998, 2001) and SKYNET (Hashimoto et al., 2012). Several inversion algorithms (e.g., King et al., 1978; Nakajima et al., 1996; Dubovik and King, 2000, 2006; Li et al., 2006) have been developed based on Sun-sky radiometers to retrieve aerosol parameters, like aerosol optical depth $(\tau)$, single-scattering albedo, absorbing aerosol optical depth ( $\left.\tau_{\mathrm{a}}, \mathrm{AAOD}\right)$, volume particle size distribution (VPSD), and the real $(n(\lambda))$ and imaginary $(k(\lambda))$ parts of CRIs corresponding to total-column atmospheric aerosols. Although VPSDs are retrieved for a wide radius range (e.g., 0.05$15 \mu \mathrm{m}$ ) with multi-bins (e.g., 22) showing fine and coarse modes clearly, the $n$ and $k$ parts of CRIs are still commonly assumed constant for both fine and coarse modes. In practice, separation of CRIs for both fine and coarse modes depends on precisely breaking down VPSDs into individual modes and dealing with spectral variation of CRIs. Prior to these key steps, a framework to characterize AERONET aerosol products with both fine and coarse modes need to be established.

\subsection{Aerosol characterization framework based on AERONET products}

In order to separate CRIs for different modes, we need to characterize AERONET aerosol products using two major assumptions: (i) AERONET VPSDs can be fitted by multipeak log-normal modes (LNMs). We choose multi-modal log-normal distributions to fit the AERONET-retrieved VPSD by the following formula:

$$
\begin{aligned}
\frac{\mathrm{d} V(r)}{\mathrm{d} \ln r} & =\sum_{i=1}^{m} \frac{C_{i}}{\sqrt{2 \pi}\left|\ln \sigma_{i}\right|} \exp \left[-\frac{1}{2}\left(\frac{\ln r-\ln r_{i}}{\ln \sigma_{i}}\right)^{2}\right] \\
m & =1,2, \ldots,
\end{aligned}
$$

where $\mathrm{d} V / \mathrm{d} \ln r$ (in unit of $\mu \mathrm{m}^{3} \mu \mathrm{m}^{-2}$ ) is the volume particle size distribution and $C_{i}\left(\mu \mathrm{m}^{3} \mu \mathrm{m}^{-2}\right), r_{i}(\mu \mathrm{m})$ and $\ln \sigma_{i}$ are the volume modal concentration, median radius and standard deviation of $\ln r_{i}$ for each LNM mode, respectively. For most cases, AERONET VPSDs can be separated by two LNMs (i.e., $m=2$ in Eq. 1), with fine and coarse modes corresponding to small-size and large-size peak LNMs, respectively. When $m$ is larger than 2, all peaks with radius $r_{i}$ less than $1.0 \mu \mathrm{m}$ can be considered as belonging to the fine mode and others belonging to the coarse mode. (ii) Fine and coarse modes have their own sub-CRIs, while the real part $(n)$ of sub-CRIs is spectrally independent, and the imaginary part $(k)$ of sub-CRIs has spectral variation as follows:

$n_{\mathrm{f} / \mathrm{c}}(\lambda)=n_{\mathrm{f} / \mathrm{c}} \quad \lambda=440,675,870,1020 \mathrm{~nm}$,

$k_{\mathrm{f} / \mathrm{c}}(\lambda)=\left\{\begin{array}{cc}k_{\mathrm{f} / \mathrm{c}, 440} & \lambda=440 \mathrm{~nm} \\ k_{\mathrm{f} / \mathrm{c}} & \lambda=675,870,1020 \mathrm{~nm},\end{array}\right.$

where $\lambda$ denotes standard wavelength of AERONET products and "f" and "c" represent the fine and coarse modes, respectively.

The above assumed spectral properties of sub-CRIs are useful to simplify subsequent procedure, and it basically fits current knowledge of aerosol properties. Figure 1 shows CRIs of various aerosol components, including black carbon, dust, organics, sulfate and aerosol water. Based on these 

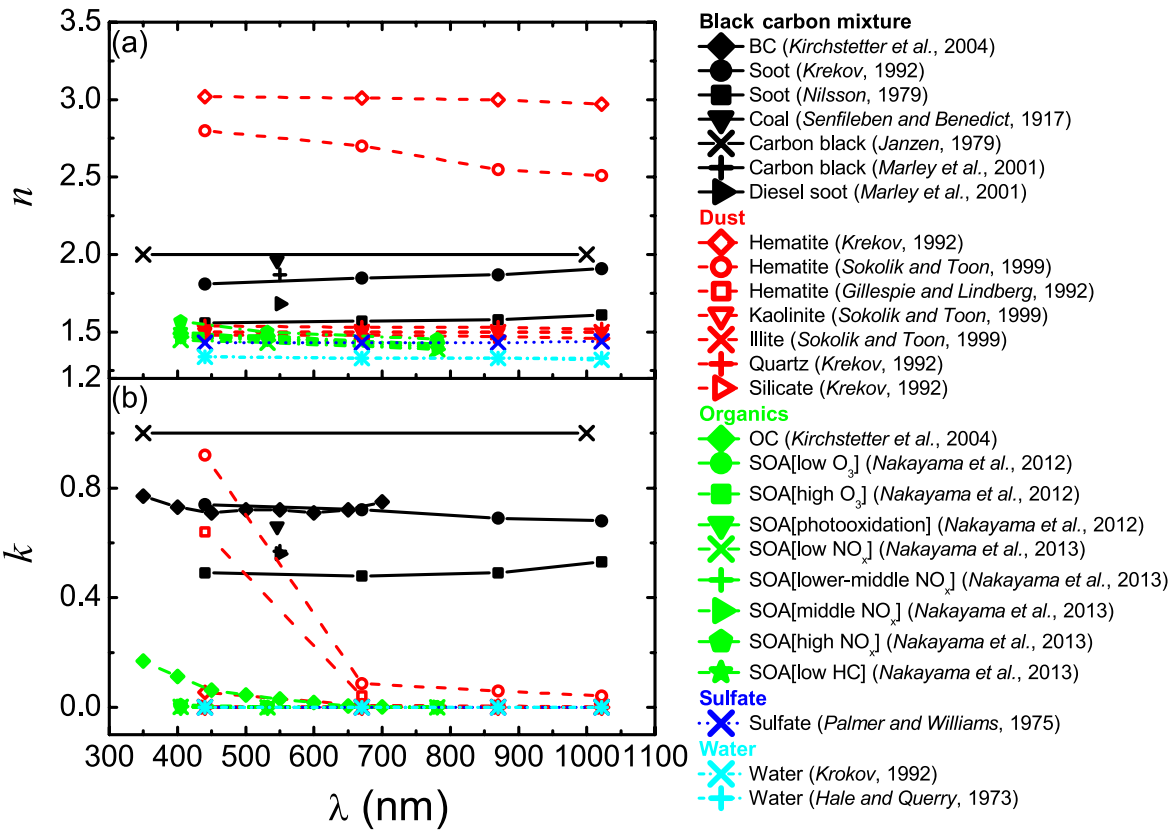

Figure 1. Complex refractive indices (real part: a; imaginary part: b) reported in the literature. Abbreviations are as follow: $\mathrm{BC}$ (black carbon), OC (organic carbon), SOA (secondary organic aerosol).

data, the CRI real parts $(n)$ of aerosol components are quite constant from UV to the near-infrared spectral region. Only hematite, following Sokolik and Toon (1999), shows some spectral variation, but its content is usually very low in aerosols, e.g., less than 5\% in mass (Schuster et al., 2016; Wagner et al., 2012; Lafon et al., 2004). In contrast, the CRI imaginary parts $(k)$ of aerosol components show significant spectral variation, especially at short wavelengths (e.g., $440 \mathrm{~nm}$ ). Again, hematite shows significantly higher absorption at $440 \mathrm{~nm}$ so that it can affect the $k$ value of entire aerosols, although with a low concentration. In addition, the imaginary part of organics shows some spectral variation (e.g., a difference of 0.123 between 350 and $500 \mathrm{~nm}$ ) while that of black carbon mixture also has a smaller spectral change, e.g., variation of about 0.05 at short wavelength.

\subsection{Size distribution breakdown}

Optical parameters (e.g., $\tau$ and $\tau_{\mathrm{a}}$ ) of aerosols are usually sensitive to the size distribution and less sensitive to the refractive indices (Zhang et al., 2013; Gobbi et al., 2007). Therefore, the separation of aerosol VPSD is the basis for the next steps of accurate estimation of sub-CRIs. The traditional size distribution breakdown approaches, e.g., cutting off fine and coarse modes from VPSD based on a fixed or dynamic particle radius, cannot naturally separate fine and coarse modes; in particular, the obtained sub-mode curve is not a complete log-normal function. Therefore, in this study, we separate the VPSD into complete log-normal functions following the VPSD breakdown method described in Cuesta et al. (2008). Firstly, we need to set the initial guess values of $r_{i}, \sigma_{i}$ and $C_{i}$ in Eq. (1). This is based on calculation of the second derivative of VPSDs and follows Eq. (4):

$$
\left\{\begin{aligned}
g(r) & =-\frac{d^{2} v(r)}{\mathrm{d} r^{2}} \\
r_{i}=g^{-1} & \left(\max _{i}(g(r))\right) \quad i=1, m \\
\sigma_{i} & =\sqrt{\frac{r_{i}^{+}}{r_{i}^{-}}} \\
C_{i} & =v\left(r_{i}\right)
\end{aligned}\right.
$$

where $v$ (instead of $\mathrm{d} V / \mathrm{d} \ln r$ ) is the AERONET VPSD and $r_{i}^{+}$and $r_{i}^{-}$are the zero-crossing points of $g(r)$ around $r_{i}$ in each mode. Then, to obtain the optimized values of these three parameters (i.e., $C_{i}, r_{i}$ and $\sigma_{i}$ ) of each peak, an iterative procedure is performed by minimizing Chi square on VPSDs (see Eq. 5) using the Nelder-Mead simplex algorithm (Nelder and Mead, 1965; Lagarias et al., 1998).

$\chi^{2}=\sum_{j=1}^{22} \frac{\left(v\left(r_{j}\right)-v_{\text {calc }}\left(r_{j}\right)\right)^{2}}{v\left(r_{j}\right)}$,

where $v$ and $v_{\text {calc }}$ are $\mathrm{d} V / \mathrm{d} \ln r$ from AERONET products recalculated from the separated fine and coarse-mode parameters, respectively, and $j$ is the bin of the AERONET VPSD. 


\subsection{Separating refractive indices for fine and coarse modes}

According to the aerosol characterization framework in Sect. 2.1, the flowchart (Fig. 2) of the fine and coarse mode CRI separation is as follows (based on the separated size distribution in Sect. 2.2):

a. Guesses of six output parameters $\left(n_{\mathrm{f}} ; k_{\mathrm{f}, 440}\right.$; $\left.k_{\mathrm{c}} ; \quad n_{\mathrm{c}} ; k_{\mathrm{c}, 440} ; k_{\mathrm{c}}\right)$. The initial guess values are set with AERONET product values: $\quad n_{\mathrm{f}}=n_{\text {AERONET }}(440 \mathrm{~nm}), \quad k_{\mathrm{f}, 440} \quad$ and $\quad k_{\mathrm{f}}=$ $k_{\text {AERONET }}(440 \mathrm{~nm}), \quad n_{\mathrm{c}}=n_{\mathrm{AERONET}}(870 \mathrm{~nm}), \quad$ and $k_{\mathrm{c}, 440}$ and $k_{\mathrm{c}}=k_{\mathrm{AERONET}}(870 \mathrm{~nm})$. Meanwhile, the boundary ranges of these parameters are set as $n_{\mathrm{f}}[1.33$, $1.6], n_{\mathrm{c}}[1.33,1.6], k_{\mathrm{f}, 440}[0.0,0.5], k_{\mathrm{c}, 440}[0.0,0.5], k_{\mathrm{f}}$ $[0.0001,0.5]$ and $k_{\mathrm{c}}[0.0001,0.5]$.

b. Calculating the effective CRI corresponding to each VPSD bin. Here, based on the guessed CRIs of both fine and coarse modes in the previous step, we employ an internal mixing approach, following the volume average rule (Heller, 1965), to estimate the CRI of each particle radius bin:

$$
\begin{gathered}
n(r)=\frac{n_{\mathrm{f}} v_{\mathrm{f}}(r)+n_{\mathrm{c}} v_{\mathrm{c}}(r)}{v_{\mathrm{f}}(r)+v_{\mathrm{c}}(r)}, \\
k(\lambda, r)=\frac{k_{\mathrm{f}} \nu_{\mathrm{f}}(r)+k_{\mathrm{c}} \nu_{\mathrm{c}}(r)}{v_{\mathrm{f}}(r)+v_{\mathrm{c}}(r)} .
\end{gathered}
$$

These CRI of each bins can be used to improve the precision of calculation of aerosol optical parameters, employed by next constraint steps.

c. Calculating aerosol optical parameters ( $\tau$ for $\lambda=440$, $500,675,870,1020 \mathrm{~nm}$ and $\tau_{\mathrm{a}}$ for $\lambda=440,675,870$, $1020 \mathrm{~nm}$; here wavelengths correspond to AERONET product bands) with the use of the aerosol CRI and VPSD of step (b) by Mie theory:

$$
\begin{gathered}
\tau(\lambda)=\int \pi r^{2} Q_{\mathrm{ex}}(\lambda, r, n(r)-i k(\lambda, r)) \cdot \frac{\mathrm{d} N(r)}{\mathrm{d} r} \cdot \mathrm{d} r \\
\tau_{\mathrm{s}}(\lambda)=\int \pi r^{2} Q_{\mathrm{sc}}(\lambda, r, n(r)-i k(\lambda, r)) \cdot \frac{\mathrm{d} N(r)}{\mathrm{d} r} \cdot \mathrm{d} r \\
\tau_{\mathrm{a}}(\lambda)=\tau(\lambda)-\tau_{\mathrm{s}}(\lambda),
\end{gathered}
$$

where $\mathrm{d} N / \mathrm{d} r$ represents the number size distribution in the atmospheric column which can be obtained from VPSD, $\tau_{\mathrm{s}}$ is the scattering aerosol optical depth, $\lambda$ is wavelength and $r$ is particle radius. $Q_{\mathrm{ex}}$ and $Q_{\mathrm{sc}}$ represent the extinction and scattering efficiency of single spherical particles, respectively.

d. Calculation of Jacobians of $\tau(\lambda)$ and $\tau_{\mathrm{a}}(\lambda)$ by disturbing each sub-CRI parameter by $0.1 \%(\Delta)$, which is needed by the optimization algorithm in step (e).

e. Finding the optimal solution based on a limited-memory optimization algorithm (L-BFGS, Broyden-FletcherGoldfarb-Shanno; Zhu et al., 1997) by constraining both $\tau(\lambda)$ and $\tau_{\mathrm{a}}(\lambda)$ with AERONET products.

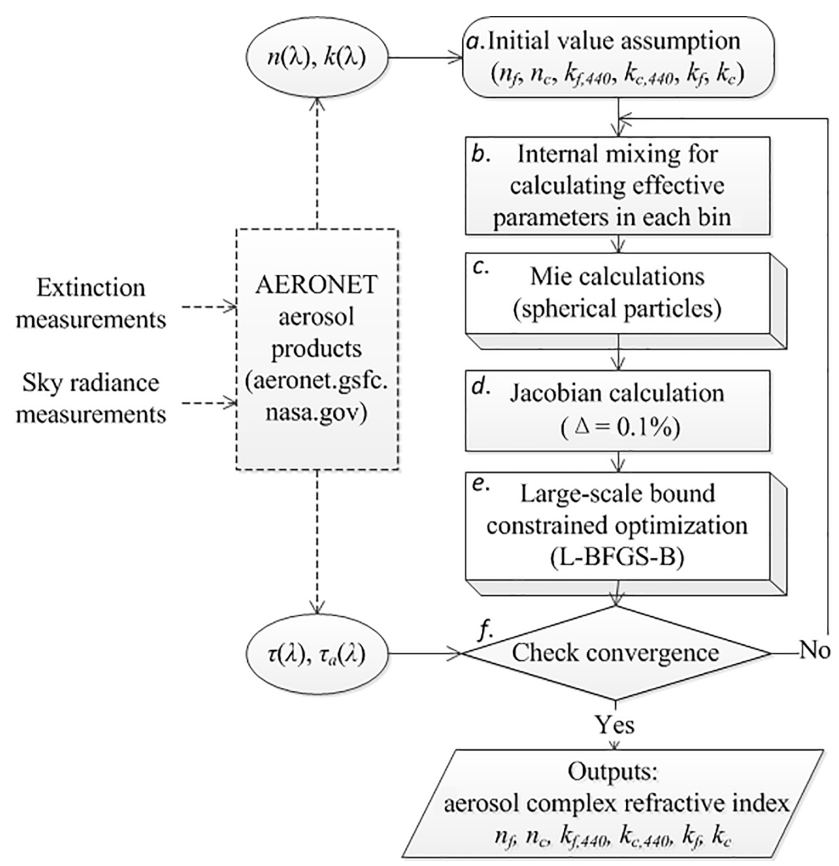

Figure 2. The flowchart of the fine and coarse mode CRI estimation scheme.

f. Checking if the convergence, $\left(f_{i}-\right.$ $\left.f_{i+1}\right) / \max \left(f_{i+1}, f_{i}, 1\right)<\eta \cdot \epsilon$, is achieved. If so, output the separated sub-CRI parameters, otherwise replace the initial guess with current solution and repeat steps (b)-(f). Here, $f$ is the Chi-square kernel function, with subscript $i$ and $i+1$ representing iteration counts, $\eta$ is a convergence control factor and $\epsilon$ is machine precision (typically setting $\eta=10^{-4} / \epsilon$ ).

\section{Numerical tests}

\subsection{Typical aerosol model test}

To test the CRI separation scheme, we employ three typical (i.e., water soluble, biomass burning and dust) aerosol type models (Table 1 ) in this paper. These aerosol type parameters are the same with Dubovik et al. (2000), except for supplementing coarse mode $n_{\mathrm{c}}$ and $k_{\mathrm{c}}(1.53-0.008 i)$ for all types and keeping original CRIs for only fine modes. Based on these microphysical characters, $\tau$ and $\tau_{\mathrm{a}}$ (Table 1) and diffused sky radiance are calculated by Mie and radiative transfer code. Then, these sky radiances are inverted by the AERONET inversion algorithm (Dubovik et al., 2000) to yield AERONET aerosol CRI products ( $n$ and $k$ ), which will be used as the inputs of our estimation scheme.

In the numerical test, the initial guess values (see Sect. 2.3) are set with the bimodal combined VPSD and $(n, k)$ of the simulated AERONET product (Table 1), additionally with typical errors of AERONET products (i.e., 0.05 in $n$ and $40 \%$ 
Table 1. Typical aerosol models (WS: water soluble, BB: biomass burning, DU: dust) and their sub-mode parameters.

\begin{tabular}{|c|c|c|c|c|c|c|c|c|c|c|c|c|c|}
\hline \multirow[t]{2}{*}{ Type } & \multicolumn{9}{|c|}{ Fine and coarse mode parameters } & \multicolumn{2}{|c|}{ AOD and AAOD by Mie } & \multicolumn{2}{|c|}{$\begin{array}{c}\text { Simulated AERONET products } \\
\text { by radiance inversion }\end{array}$} \\
\hline & $r_{1}$ & $r_{2}$ & $\sigma_{1}$ & $\sigma_{2}$ & $C_{1} / C_{2}$ & $n_{\mathrm{f}}$ & $k_{\mathrm{f}}$ & $n_{\mathrm{c}}$ & $k_{\mathrm{c}}$ & $\begin{array}{r}\tau \\
(440 / 500 / 675 / \\
870 / 1020 \mathrm{~nm})\end{array}$ & $\begin{array}{r}\tau_{\mathrm{a}} \\
(440 / 675 / \\
870 / 1020 \mathrm{~nm})\end{array}$ & $\begin{array}{r}n \\
(440 / 675 / \\
870 / 1020 \mathrm{~nm})\end{array}$ & $\begin{array}{r}k \\
(440 / 675 / \\
870 / 1020 \mathrm{~nm})\end{array}$ \\
\hline WS & 0.118 & 1.17 & 0.6 & 0.6 & 2 & 1.45 & 0.0035 & 1.53 & 0.008 & $\begin{array}{r}0.50 / 0.41 / 0.25 / \\
0.17 / 0.14\end{array}$ & $\begin{array}{r}0.02 / 0.01 / \\
0.01 / 0.01\end{array}$ & $\begin{array}{r}1.45 / 1.45 / \\
1.46 / 1.47\end{array}$ & $\begin{array}{r}0.0042 / 0.0039 / \\
0.0045 / 0.0047\end{array}$ \\
\hline BB & 0.132 & 4.5 & 0.4 & 0.6 & 4 & 1.52 & 0.025 & 1.53 & 0.008 & $\begin{array}{r}0.50 / 0.39 / 0.21 / \\
0.11 / 0.08\end{array}$ & $\begin{array}{r}0.06 / 0.03 / \\
0.02 / 0.02\end{array}$ & $\begin{array}{r}1.52 / 1.51 / \\
1.52 / 1.51\end{array}$ & $\begin{array}{r}0.0226 / 0.0199 / \\
0.0214 / 0.0216\end{array}$ \\
\hline DU & 0.1 & 3.4 & 0.6 & 0.8 & 0.066 & 1.53 & 0.008 & 1.53 & 0.008 & $\begin{array}{r}0.50 / 0.46 / 0.40 / \\
0.38 / 0.37\end{array}$ & $\begin{array}{r}0.09 / 0.07 / \\
0.06 / 0.06\end{array}$ & $\begin{array}{r}1.54 / 1.51 / \\
1.52 / 1.53\end{array}$ & $\begin{array}{r}0.0085 / 0.0073 / \\
0.0089 / 0.0090\end{array}$ \\
\hline
\end{tabular}

in $k$; Dubovik et al., 2000), in order to test the scheme tolerance on the initial guess biases. In Fig. 3 we present the separated sub-mode CRIs of three typical models and the breakdown results of VPSD (Fig. 3). It can be seen that both the real and imaginary parts of fine and coarse modes are well separated. The maximum error of the real part is 0.046 attached to the $n_{\mathrm{c}}$ of the biomass burning type, while the error of the imaginary part is 0.003 for $k_{\mathrm{f}, 440}$ of the biomass burning. The uncertainty of the $n_{\mathrm{c}}$ can be understood as the optical contribution of coarse mode is weak in the case of biomass burning type and is thus difficult to retrieve. Meanwhile, as compensation, the imaginary part $k_{\mathrm{f}}$ is also biased in this case. Moreover, from the right column of Fig. 3 we can see that LNM breakdown is perfectly achieved for each type with very small residuals $\left(<6.0 \times 10^{-5}\right)$, which guarantees the retrieval performance on sub-mode CRIs.

Figure 4 shows the recovery of $\tau$ and $\tau_{\mathrm{a}}$ (see step e) of Sect. 2.3) and the comparison with true values listed in Table 1. On average, we find fairly good agreements for fitting the spectral $\tau$ and $\tau_{\mathrm{a}}$. The absolute $\tau$ error of $1.33 \times 10^{-2}$ at $440 \mathrm{~nm}$ in dust type is relatively larger than other wavelengths but still small enough considering that the AERONET AOD measurement uncertainty is about $0.01-$ 0.02 . The maximum error when fitting $\tau_{\mathrm{a}}$ is about $0.55 \times$ $10^{-2}$, corresponding to biomass burning at $440 \mathrm{~nm}$. The largest root-mean-square error (RMSE) when fitting $\tau$ appears in the dust type, corresponding to the underestimate of $n_{\mathrm{f}}$ and $n_{\mathrm{c}}$ (Fig. 3). Similarly, the overestimated $k_{\mathrm{f}, 440}$ and $k_{\mathrm{f}}$ in the biomass burning type also leads to a relatively larger RMSE $\left(3.34 \times 10^{-3}\right)$ when fitting $\tau_{\mathrm{a}}$.

\subsection{Error estimation}

In order to evaluate the overall performance of the estimation scheme, we perform numerical experiments to assess errors of output sub-mode CRI parameters related to (i) uncertainties on $\tau$. We set typical $\tau$ uncertainty (here, 0.01) of AERONET products (Holben et al., 1998; Eck et al., 1999) for all $\tau$ bands: (ii) uncertainties on $\tau_{\mathrm{a}}$. Because $\tau_{\mathrm{a}}$ of AERONET is obtained by multiplying $\tau$ with the singlescattering albedo $(\omega)$, we consider here $\omega$ uncertainty $(0.03)$ of AERONET products (Dubovik et al., 2000) and estimate the uncertainty of $\tau_{\mathrm{a}}$ by error propagation: (iii) uncertainties on VPSD. We set three typical VPSD (22 bins) uncertainties $(15,25$ and $35 \%$ for the average of all bins) of AERONET products following Dubovik et al. (2000), corresponding to the inversion uncertainties on VPSDs of watersoluble, biomass burning and dust aerosol types.

Table 2 presents retrieval errors of six sub-mode CRI parameters associated with three typical aerosol types. For the reason of simplification, we only show the impacts of $\Delta \tau=0.01, \Delta \omega=-0.03$ and the positive error on VPSDs, considering that biases caused by input parameter uncertainties are usually symmetric around real values for such kind of retrieval algorithms ( $\mathrm{Li}$ et al., 2006). For the influence of $\Delta \tau=0.01$, it can be seen that retrieval errors are relatively small. The largest error caused by $\Delta \tau=0.01$ is seen in $k_{\mathrm{f}}$ (dust type), which is 0.0023 . As to the influence of $\Delta \omega=-0.03$, the retrieval errors increase, especially for the imaginary parts, e.g., $\Delta k_{\mathrm{c}}=0.0074$ for water-soluble types. The errors caused by uncertainty in the VPSD are quite different for the real and imaginary parts of CRI. The retrieval errors of $n_{\mathrm{f}}$ and $n_{\mathrm{c}}$ are larger than those of $k_{\mathrm{f}}$ and $k_{\mathrm{c}}$, with a maximum $\Delta n_{\mathrm{f}}$ of 0.200 in the case of dust type. As a summary of Table 2, considering that it looks like not all uncertainties reach the maximum simultaneously, and based on error propagation theory, the total uncertainties on the retrieved sub-mode CRI parameters are estimated as $\Delta n_{\mathrm{f}}=$ $0.106, \Delta k_{\mathrm{f}}=50.6 \%\left(\Delta k_{\mathrm{f}, 440}=75.4 \%\right)$ and $\Delta n_{\mathrm{c}}=0.111$, $\Delta k_{\mathrm{c}}=77.8 \%\left(\Delta k_{\mathrm{c}, 440}=56.1 \%\right)$ for the average of all typical aerosol types, or, more simplified, the expected errors of sub-mode CRIs are $\Delta n_{\mathrm{f} / \mathrm{c}}=0.11$ and $\Delta k_{\mathrm{f} / \mathrm{c}, 440}=78 \%$, which are about 2 times larger than those of AERONET products of all-size CRIs (i.e., $\Delta n=0.04$ and $\Delta k=40 \%$ ). This is acceptable and logical considering that we are separating mixed information and these uncertainties are still acceptable for most applications, e.g., validation of chemical models. 

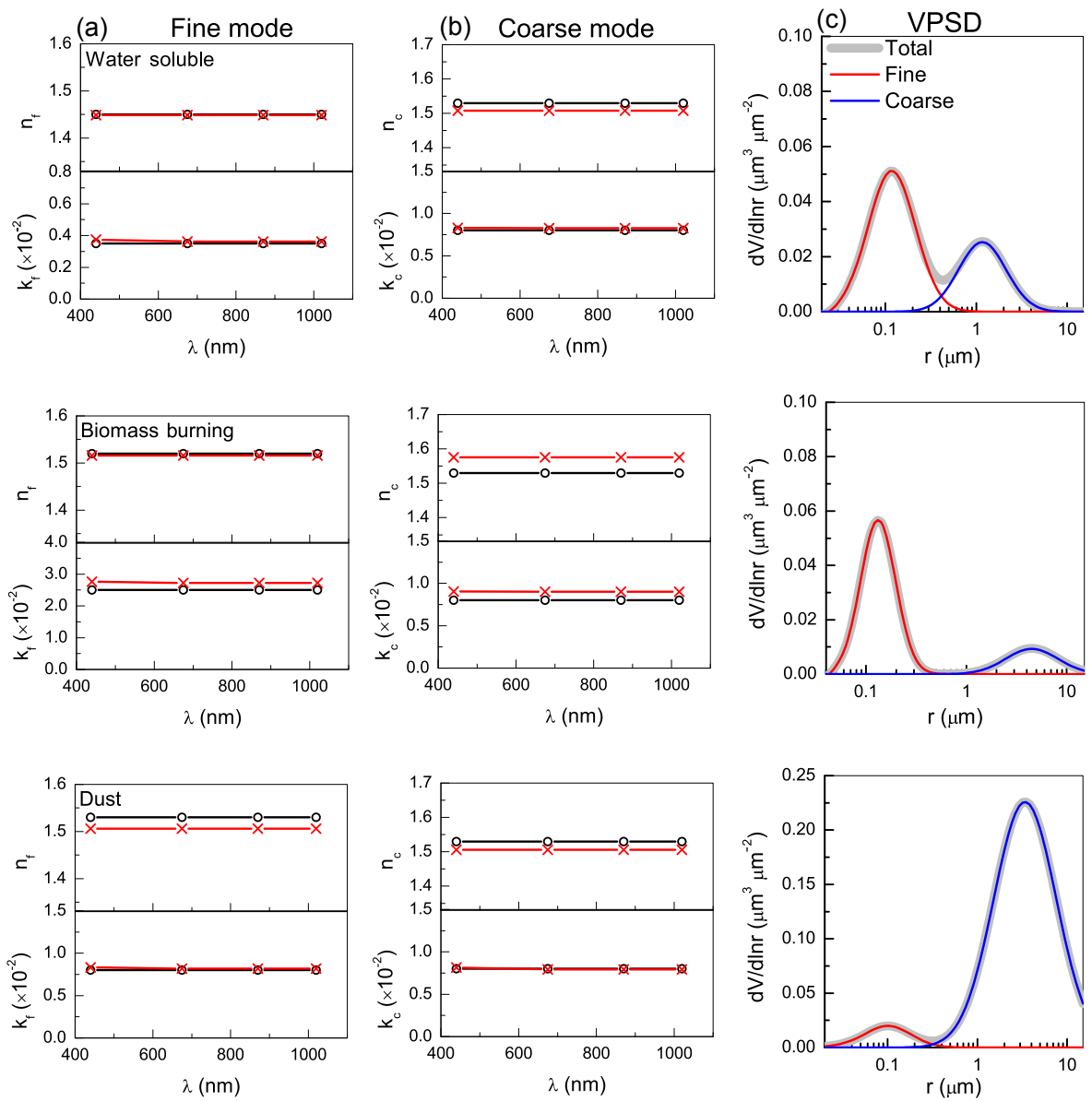

Figure 3. Estimation of complex refractive indices for both fine (a) and coarse (b) modes of three aerosol types (each row). True values are in circles and retrieved values are in cross symbols. The volume particle size distributions and corresponding breakdown results (c) are also shown.
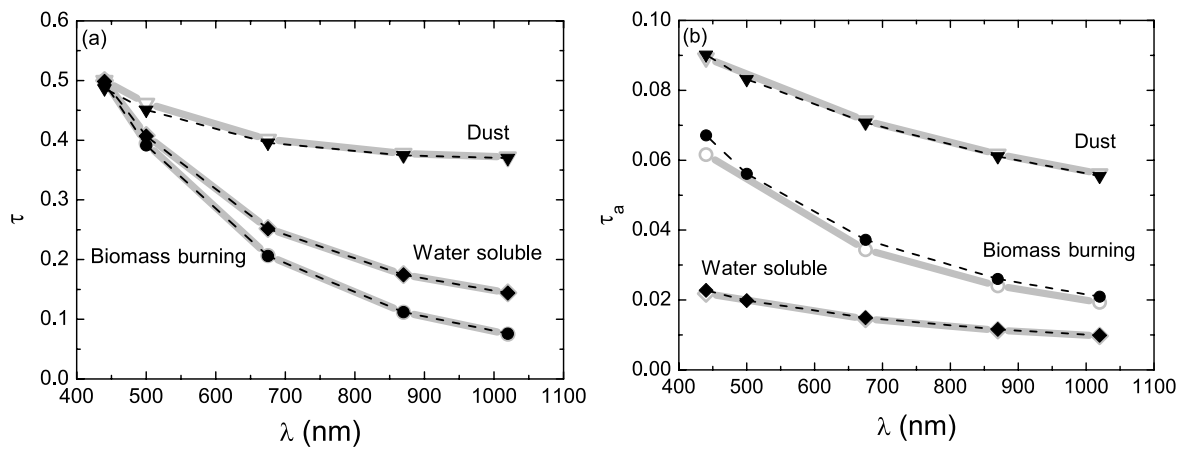

Figure 4. Recovery of spectral $\tau$ (left) and $\tau_{\mathrm{a}}$ (right) for three aerosol types (thick line: true; thin line: recovered, corresponding to the separated sub-mode CRIs in Fig. 3).

\subsection{Discussion on the sensitivity}

As shown in Sect. 3.1, retrieval performance on the fine and coarse modes can be different with respect to the real and imaginary parts of CRI; for example, for the real part, $\Delta n_{\mathrm{f}}$ is significantly less than $\Delta n_{\mathrm{c}}$ in the case of biomass burning aerosols. This suggests that the natural properties of aerosol modes may affect the accuracy of sub-mode CRI estimation, and it is thus necessary to perform a simple sensitivity study to further clarify the retrieval possibility and possible limitations in addition to the numerical error estimation in Sect. 3.2. 
Table 2. Typical uncertainties on the estimated complex refractive indices of fine (f) and coarse (c) modes. Three error sources (on $\tau, \tau_{\mathrm{a}}$ and VPSD, respectively) and three aerosol types (WS: water soluble, BB: biomass burning, DU: dust) are considered.

\begin{tabular}{|c|c|c|c|c|c|c|c|c|}
\hline \multirow{2}{*}{\multicolumn{2}{|c|}{ Error sources }} & \multirow{2}{*}{ Aerosol types } & \multicolumn{3}{|c|}{ Fine mode } & \multicolumn{3}{|c|}{ Coarse mode } \\
\hline & & & $\Delta n_{\mathrm{f}}$ & $\Delta k_{\mathrm{f}, 440}$ & $\Delta k_{\mathrm{f}}$ & $\Delta n_{\mathrm{c}}$ & $\Delta k_{\mathrm{c}, 440}$ & $\Delta k_{\mathrm{c}}$ \\
\hline \multirow{3}{*}{\multicolumn{2}{|c|}{$\Delta \tau=0.01$}} & WS & 0.010 & 0.0004 & 0.0003 & 0.006 & 0.0009 & 0.0008 \\
\hline & & $\mathrm{BB}$ & 0.010 & 0.0001 & 0.0007 & 0.044 & 0.0016 & 0.0014 \\
\hline & & DU & 0.026 & 0.0017 & 0.0023 & 0.020 & 0.0003 & 0.0002 \\
\hline \multirow{3}{*}{\multicolumn{2}{|c|}{$\Delta \omega=-0.03\left(\right.$ proxy of $\left.\Delta \tau_{\mathrm{a}}\right)$}} & WS & 0.001 & 0.0033 & 0.0001 & 0.037 & 0.0066 & 0.0074 \\
\hline & & BB & 0.005 & 0.0073 & 0.0037 & 0.046 & 0.0011 & 0.0012 \\
\hline & & DU & 0.008 & 0.0019 & 0.0018 & 0.044 & 0.0021 & 0.0026 \\
\hline \multirow[t]{3}{*}{$\triangle \mathrm{VPSD}=$} & $15 \%$ & WS & 0.048 & 0.0007 & 0.0007 & 0.157 & 0.0032 & 0.0004 \\
\hline & $25 \%$ & BB & 0.066 & 0.0042 & 0.0045 & 0.060 & 0.0021 & 0.0021 \\
\hline & $35 \%$ & DU & 0.200 & 0.0072 & 0.0080 & 0.070 & 0.0024 & 0.0080 \\
\hline \multicolumn{3}{|c|}{ Total error estimation* } & 0.106 & $75.41 \%$ & $50.62 \%$ & 0.111 & $56.05 \%$ & $77.76 \%$ \\
\hline
\end{tabular}

* Total error estimation $=\sqrt{\bar{x}_{\Delta \tau}^{2}+\bar{x}_{\Delta \tau_{\mathrm{a}}}^{2}+\bar{x}_{\Delta \mathrm{VPSD}}^{2}}$, where $\bar{x}$ represents the mean error of sub-CRIs from three aerosol types.

Firstly, we disturb the scheme outputs (e.g., aerosol subCRI parameters) by their expected errors (i.e., $\delta n=0.111$ and $\delta k=77.8 \%$ ) as assessed in Sect. 3.2. Then, by utilizing three aerosol type (WS, BB and DU) models, we trace the effects of these perturbations on the scheme constrain parameters, i.e., $\tau$ and $\tau_{\mathrm{a}}$. Finally, we compare these perturbation results $\left(\delta \tau / \tau\right.$ and $\left.\delta \tau_{\mathrm{a}} / \tau_{\mathrm{a}}\right)$ with their corresponding sensitivity thresholds (e.g., measurement uncertainties) - here $\delta \tau / \tau=2 \%$ and $\delta \tau_{\mathrm{a}} / \tau_{\mathrm{a}}=6 \%$ for AERONET measurements. If the perturbation results are generally beyond the sensitivity thresholds, we can confirm that the constraint parameters are sensitive to the scheme outputs. It should be mentioned that we simultaneously employ $\tau$ and $\tau_{\mathrm{a}}$ as the constraints in our estimation scheme. In other words, this suggest that both $\tau$ and $\tau_{\mathrm{a}}$ sensitivities contribute to the convergence of the iterative scheme. When given only one sensitive parameter ( $\tau$ or $\tau_{\mathrm{a}}$ ), it is still possible to constrain the inversion scheme.

As illustrated in Fig. 5, we find that $\tau$ is mainly sensitive to the $n_{\mathrm{f}}$ of the WS and BB types, and their sensitivity curves decrease with the wavelength. Although the relatively low sensitivity to $n_{\mathrm{f}}$ is present in the DU type, $\delta \tau / \tau$ is still higher than the sensitivity threshold for this case. In contrast, the sensitivity of $k_{\mathrm{f}}$ increases with wavelength, while the much higher sensitivity of $k_{\mathrm{f}}$ is seen in $\tau_{\mathrm{a}}$. The sensitivities of $n_{\mathrm{c}}$ of all three types are considerably low, e.g., the largest sensitivity in $\tau_{\mathrm{a}}$ is less than $3 \%$. Meanwhile, $\tau_{\mathrm{a}}$ is sensitive to both $k_{\mathrm{c}}$ and $k_{\mathrm{f}}$ components except for the fine mode of dust types and coarse mode of biomass burning types, with a maximum sensitivity of $43 \%$ ( $k_{\mathrm{f}}$ of biomass burning). The sensitivity of dust type shows a good qualitative agreement with previous studies (Dubovik et al., 2000; Wendisch and von Hoyningenhuene, 1994).

\section{Test with AERONET data}

The sub-mode CRI estimation scheme can be directly applied to AERONET products. As a realistic test, we chose 1-year AERONET measurements at Beijing, China, considering its complex aerosol sources and properties resulting from diversified anthropogenic and natural activities. We utilize AERORNET level 2.0 (data quality assured) data at the Beijing CAMS site from April 2014 to April 2015.

The results show that the mean CRI of fine mode in Beijing is $1.48-0.010 i$ (while imaginary part at $440 \mathrm{~nm}$ is 0.012 ) and that of coarse mode is $1.49-0.004 i$ (while imaginary part at $440 \mathrm{~nm}$ is 0.007$)$. These values suggest that the fine mode real part refractive index $\left(n_{\mathrm{f}}\right)$ values are slightly lower than those of coarse mode $\left(n_{\mathrm{c}}\right)$, while fine mode imaginary part refractive index $\left(k_{\mathrm{f}}\right)$ values are significantly higher than those of coarse mode $\left(k_{\mathrm{c}}\right)$ in Beijing. Moreover, both fine and coarse modes have larger imaginary parts at $440 \mathrm{~nm}$ than other wavelengths from 675 to $1020 \mathrm{~nm}$. These results have similar trends as compared with Fig. 1 and agree with Hand and Kreidenweis (2002).

For more details, the seasonal mean values of CRIs of fine and coarse modes in Beijing are shown in Fig. 6. It can be seen that (i) both $n_{\mathrm{f}}$ and $n_{\mathrm{c}}$ are the lowest in summer (Fig. 6a), which agrees with the maximum humidity of summer in Beijing, because higher aerosol water $(n=1.33)$ content tends to decrease for the real part of the CRI. Meanwhile, we found that the discrepancy between $n_{\mathrm{f}}$ and $n_{\mathrm{c}}$ also reaches the maximum in summer. Considering that it is generally recognized that coarse particles are weakly hygroscopic, this discrepancy suggests that the hygroscopicity of fine particles is significantly increased in summer under high-humidity conditions. (ii) For all seasons, $k_{\mathrm{c}}$ is quite constant (Fig. 6b). This suggests that large-size particulate components are relatively stable in Beijing. In contrast, $k_{\mathrm{f}}$ shows highly seasonal vari- 

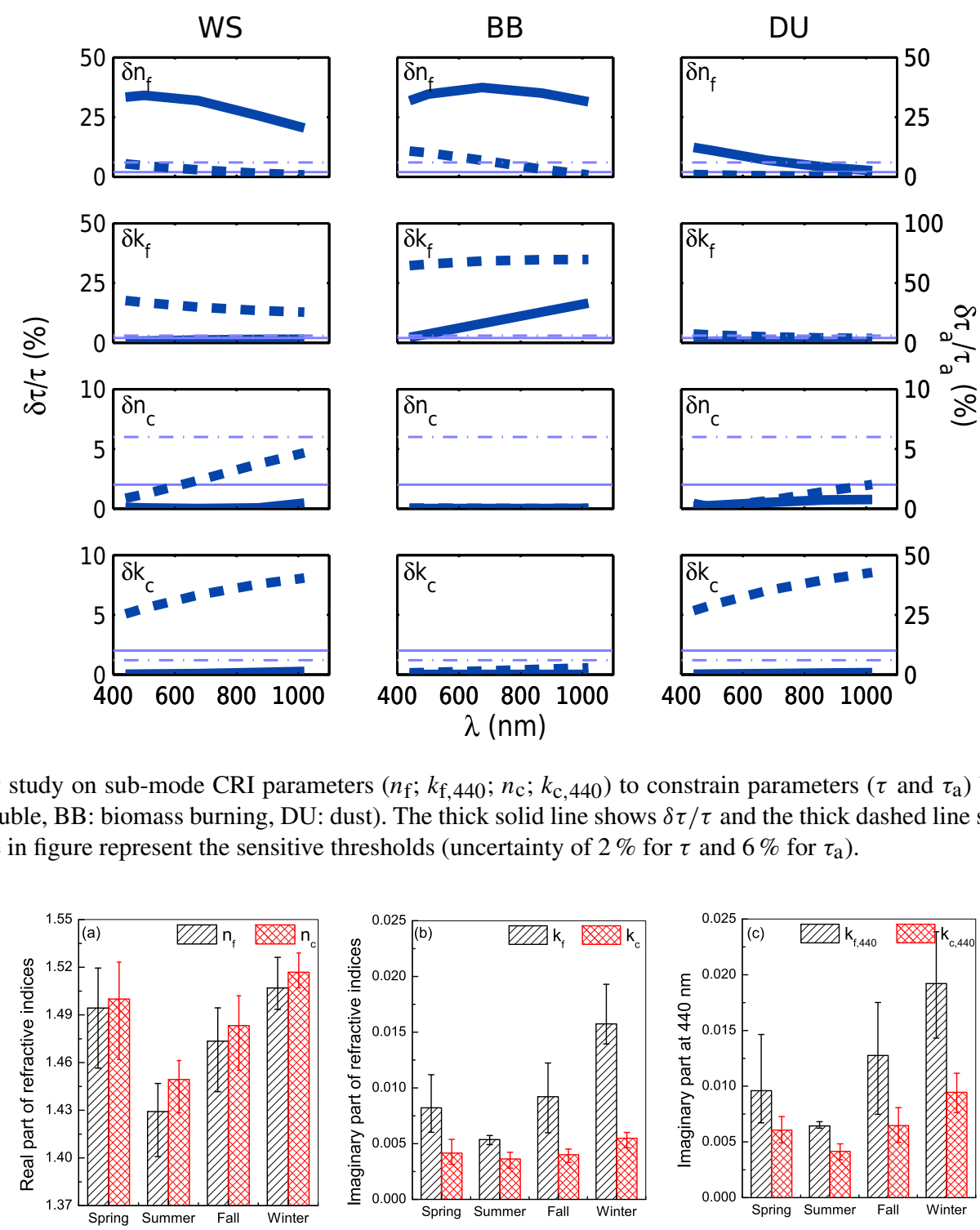

Figure 5. Sensitivity study on sub-mode CRI parameters $\left(n_{\mathrm{f}} ; k_{\mathrm{f}, 440} ; n_{\mathrm{c}} ; k_{\mathrm{c}, 440}\right)$ to constrain parameters $\left(\tau\right.$ and $\left.\tau_{\mathrm{a}}\right)$ based on three aerosol types (WS: water soluble, BB: biomass burning, DU: dust). The thick solid line shows $\delta \tau / \tau$ and the thick dashed line shows $\delta \tau_{\mathrm{a}} / \tau_{\mathrm{a}}$. The thin solid and dashed line in figure represent the sensitive thresholds (uncertainty of $2 \%$ for $\tau$ and $6 \%$ for $\tau_{\mathrm{a}}$ ).
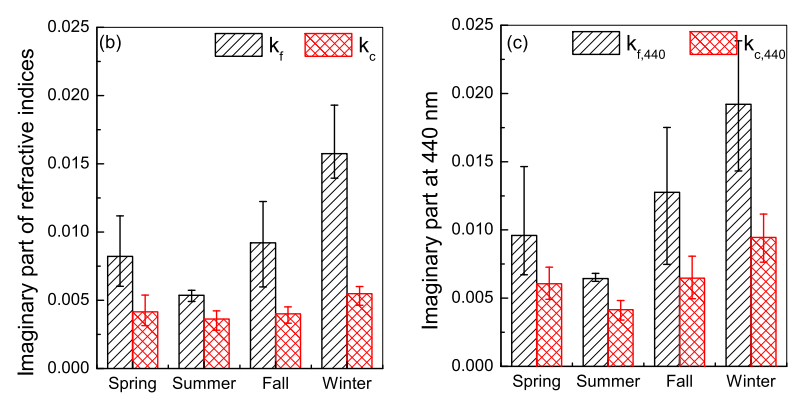

Figure 6. Seasonal mean of the real part (a), imaginary part (b) and imaginary part at $440 \mathrm{~nm}$ (c) of sub-mode aerosol refractive indices in Beijing 2014-2015. The "f" and "c" subscripts denote the fine and coarse mode respectively. Error bar shows the maximum and minimum of the monthly mean values.

ation and the winter value is about 3 times higher than summer, which can be explained by the increase of carbonaceous component emissions during Beijing's winter heating season (Jing et al., 2013). (iii) In Fig. 6c, it can be seen that the characteristics of $k_{\mathrm{f}}$ and $k_{\mathrm{c}}$ are similar to those of $k_{\mathrm{f}, 440}$ and $k_{\mathrm{c}, 440}$, except for the enlarged seasonal variation amplitude (especially for $\left.k_{\mathrm{c}, 440}\right)$. Compared with Fig. 1, we thought that this might be caused by hematite. As jointly seen with Fig. 6b, $k_{\mathrm{c}, 440}$ decreases significantly in summer, which may suggest that the decrease of hematite is stronger in summer. This indicates some clues on the component changes of coarse particles; for example, the invaded dust (higher hematite concentration) might be prohibited significantly in summer due to higher humidity and surface roughness, while the local emission of large particles mainly consists of non-mineral components.

In Fig. 7, we illustrate the recovery of scheme input parameters (AERONET $\tau$ and $\tau_{\mathrm{a}}$ ). It can be seen that the maximum averaged bias (relatively $10 \%$ and absolutely 0.029 ) occurs at $1020 \mathrm{~nm}$. Meanwhile the maximum bias (relatively $11 \%$ and absolutely 0.002) in $\tau_{\mathrm{a}}$ is also attached to this longer wavelength. These biases are basically close to our expectation and claimed uncertainties of AERONET products ( $\tau$ and $\tau_{\mathrm{a}}$ ) and thus prove that our sub-mode CRI results are acceptable in the understanding of optical closure. 

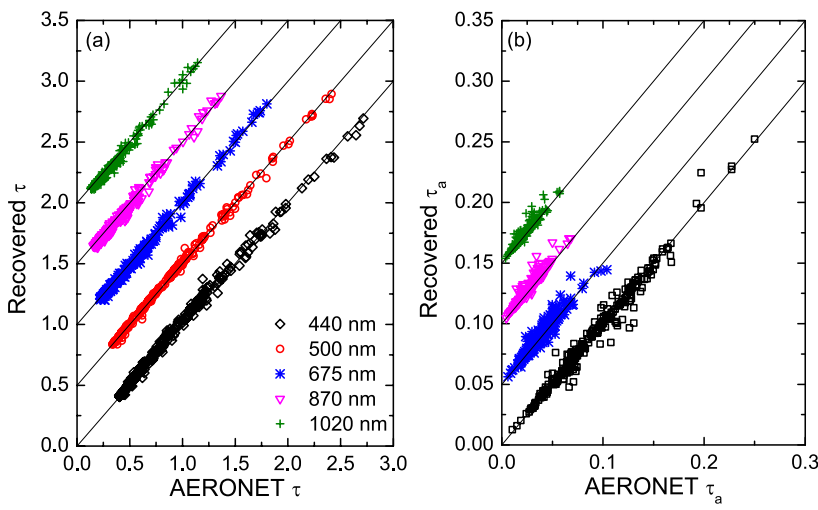

Figure 7. Recovery of $\tau$ and $\tau_{\mathrm{a}}$ based on the separated sub-mode aerosol complex refractive indices. $N=259$ and curves are shifted for a better viewing.

\section{Conclusions}

This paper establishes a scheme to estimate complex refractive indices of both fine and coarse aerosol modes for the total-column atmosphere. The input parameters of the scheme are the volume particle size distribution, spectral aerosol optical depth $(\tau)$ and absorbing aerosol optical depth $\left(\tau_{\mathrm{a}}\right)$ of AERONET aerosol products, while AERONET complex refractive index products are used to generate the initial guesses. The retrieval outputs are aerosol CRIs separated for fine $\left(n_{\mathrm{f}}, k_{\mathrm{f}, 440}, k_{\mathrm{f}}\right)$ and coarse modes $\left(n_{\mathrm{c}}, k_{\mathrm{c}, 440}, k_{\mathrm{c}}\right)$ simultaneously. We present the VPSD breakdown and sub-mode CRI iterative inversion techniques as well as the error estimation and test with AERONET real measurements at the Beijing site.

The numerical test with three aerosol types shows that submode CRIs can be well retrieved theoretically with maximum errors less than about 0.046 (real) and 0.003 (imaginary). The total uncertainties on the retrieved CRIs, by considering possible input AERONET parameter errors together, are about $\Delta n_{\mathrm{f} / \mathrm{c}}=0.11$ and $\Delta k_{\mathrm{f} / \mathrm{c}, 440}=78 \%$. Scheme tests based on real measurements are performed at the AERONET site in Beijing from 2014 to 2015 . The results suggest a CRI of $1.48-0.010 i\left(k_{\mathrm{f}, 440}=0.012\right)$ for fine mode particles and $1.49-0.004 i\left(k_{\mathrm{c}, 440}=0.007\right)$ for coarse mode aerosol particles. Retrieval results also reveal that CRIs of both fine and coarse particles have distinct characteristics in summer versus other seasons, which is due to a difference of hygroscopic effects on fine and coarse particles, as revealed by separated CRI parameters. Meanwhile, results suggest that CRIs of fine particles in winter season, especially the imaginary part, are significantly affected by anthropogenic activities, e.g., carbonaceous components from winter heating.

In future studies, we will focus on the influence of nonsphericity on dust aerosols, which may help to decrease uncertainties on CRIs of coarse mode particles. In addition, this method is not limited to AERONET remote sensing products and also applicable to in situ measurements, e.g., the joint extinction, absorption and size distribution observation obtained from measurements in real time.

Data availability. The data used for this study are available at https://www.researchgate.net/publication/319329141_CRIs_of_ fine_and_coarse_mode_in_Beijing (Zhang, 2017).

Competing interests. The authors declare that they have no conflict of interest.

Acknowledgements. This work was supported by the National Natural Science Fund of China (no. 41601386, 91544219, 41671367) and the China High-Resolution Earth Observation System (30Y20A39-9003-15/17).

Edited by: Alexander Kokhanovsky

Reviewed by: four anonymous referees

\section{References}

Boucher, O., Randall, D., Artaxo, P., Bretherton, C., Feingold, G., Forster, P., Kerminen, V.-M., Kondo, Y., Liao, H., Lohmann, U., Rasch, P., Satheesh, S. K., Sherwood, S., Stevens, B., and Zhang, X. Y.: Clouds and Aerosols. In: Climate Change 2013: The Physical Science Basis. Contribution of Working Group I to the Fifth Assessment Report of the Intergovernmental Panel on Climate Change, edited by: Stocker, T. F., Qin, D., Plattner, G.-K., Tignor, M., Allen, S. K., Boschung, J., Nauels, A., Xia, Y., Bex, V., and Midgley, P. M., Cambridge University Press, Cambridge, United Kingdom and New York, NY, USA, 2013.

Cuesta, J., Flamant, P. H., and Flamant, C.: Synergetic technique combining elastic backscatter lidar data and sunphotometer AERONET inversion for retrieval by layer of aerosol optical and microphysical properties, Appl. Optics., 47, 4598-4611, 2008.

Dinar, E., Mentel, T. F., and Rudich, Y.: The density of humic acids and humic like substances (HULIS) from fresh and aged wood burning and pollution aerosol particles, Atmos. Chem. Phys., 6, 5213-5224, https://doi.org/10.5194/acp-6-5213-2006, 2006.

Dubovik, O. and King, M. D.: A flexible inversion algorithm for retrieval of aerosol optical properties from Sun and sky radiance measurements, J. Geophys. Res.-Atmos., 105, 20673-20696, 2000.

Dubovik, O., Smirnov, A., Holben, B. N., King, M. D., Kaufman, Y. J., Eck, T. F., and Slutsker, I.: Accuracy assessments of aerosol optical properties retrieved from aerosol robotic network (AERONET) Sun and sky radiance measurements, J. Geophys. Res.-Atmos., 105, 9791-9806, 2000.

Dubovik, O., Sinyuk, A., Lapyonok, T., Holben, B. N., Mishchenko, M., Yang, P., Eck, T. F., Volten, H., Munoz, O., Veihelmann, B., van der Zande, W. J., Leon, J. F., Sorokin, M., and Slutsker, I.: Application of spheroid models to account for aerosol particle nonsphericity in remote sensing of desert dust, J. Geophys. Res.- 
Atmos., 111, D11208, https://doi.org/10.1029/2005JD006619, 2006.

Eck, T. F., Holben, B. N., Reid, J. S., Dubovik, O., Smirnov, A., O'Neill, N. T., Slutsker, I., and Kinne, S.: Wavelength dependence of the optical depth of biomass burning, urban, and desert dust aerosols, J. Geophys. Res.-Atmos., 104, 3133331349, 1999.

Gillespie, J. B. and Lindberg, J. D.: Ultraviolet and visible imaginary refractive-index of strongly absorbing atmospheric particulate matter, Appl. Opt., 31, 2112-2115, 1992.

Gobbi, G. P., Kaufman, Y. J., Koren, I., and Eck, T. F.: Classification of aerosol properties derived from AERONET direct sun data, Atmos. Chem. Phys., 7, 453-458, https://doi.org/10.5194/acp-7453-2007, 2007.

Hale, G. M. and Querry, M. R.: Optical-constants of water in $200 \mathrm{~nm}$ to $200 \mathrm{~mm}$ wavelength region, Appl. Opt., 12, 555-563, 1973.

Hand, J. L. and Kreidenweis, S. M.: Anew method for retrieving particle refractive index and effective density from aerosol size distribution data, Aerosol Sci. Technol., 36, 1012-1026, 2002.

Hashimoto, M., Nakajima, T., Dubovik, O., Campanelli, M., Che, H., Khatri, P., Takamura, T., and Pandithurai, G.: Development of a new data-processing method for SKYNET sky radiometer observations, Atmos. Meas. Tech., 5, 2723-2737, https://doi.org/10.5194/amt-5-2723-2012, 2012.

Heller, W.: Remarks on refractive index mixture rules, J. Phys. Chem.-Us., 69, 1123-1129, https://doi.org/10.1021/J100888a006, 1965.

Holben, B. N., Eck, T. F., Slutsker, I., Tanre, D., Buis, J. P., Setzer, A., Vermote, E., Reagan, J. A., Kaufman, Y. J., Nakajima, T., Lavenu, F., Jankowiak, I., and Smirnov, A.: AERONET - a federated instrument network and data archive for aerosol characterization, Remote. Sens. Environ., 66, 1-16, 1998.

Holben, B. N., Tanre, D., Smirnov, A., Eck, T. F., Slutsker, I., Abuhassan, N., Newcomb, W. W., Schafer, J. S., Chatenet, B., Lavenu, F., Kaufman, Y. J., Castle, J. V., Setzer, A., Markham, B., Clark, D., Frouin, R., Halthore, R., Karneli, A., O’Neill, N. T., Pietras, C., Pinker, R. T., Voss, K., and Zibordi, G.: An emerging ground-based aerosol climatology: aerosol optical depth from AERONET, J. Geophys. Res.-Atmos., 106, 12067-12097, 2001.

Janzen, J.: The refractive index of colloidal carbon, Journal of Colloid and Interface Science, 69, 436-447, 1979.

Kaufman, Y. J., Tanrè, D., Dubovik, O., Karnieli, A., and Remer, L. A.: Absorption of sunlight by dust as inferred from satellite and groundbased measurements, Geophys. Res. Lett., 28, 14791482, 2001.

King, M. D., Byrne, D. M., Herman, B. M., and Reagan, J. A.: Aerosol Size Distributions Obtained by Inversion of Spectral Optical Depth Measurements, J. Atmos. Sci., 1978, 2153-2167, 1978.

Kirchstetter, T. W., Novakov, T., and Hobbs, P. V.: Evidence that the spectral dependence of light absorption by aerosols is affected by organic carbon, J. Geophys. Res., 109, D21208, https://doi.org/10.1029/2004JD004999, 2004.

Kostenidou, E., Pathak, R. K., and Pandis, S. N.: An algorithm for the calculation of secondary organic aerosol density combining AMS and SMPS data, Aerosol Sci. Technol., 41, 1002-1010, 2007.
Krekov, G. M.: Models of atmospheric aerosols in Aerosol Effects on Climate, edited by: Jennings, S. G., 9-72, Univ. of Ariz. Press, Tucson, 1992.

Lafon, S., Rajot, J.-L., Alfaro, S., and Gaudichet, A.: Quanlitification of iron oxides in desert aerosol, Atmos. Environ., 38, 12111218, 2004.

Lagarias, J. C., Reeds, J. A., Wright, M. H., and Wright, P. E.: Convergence properties of the Nelder - Mead simplex method in low dimensions, SIAM J. Optim., 9, 112-147, 1998.

Li, Z. Q., Goloub, P., Devaux, C., Gu, X., Deuze, J.-L., Qiao, Y., and Zhao, F.: Retrieval of aerosol optical and physical properties from ground-based spectral, multi-angular, and polarized sunphotometer measurements, Remote Sens. Environ., 101, 519533, 2006.

Malloy, Q. G. J., Nakao, S., Qi, L., Austin, R., Stothers, C., Hagino, H., and Cocker III, D. R.: Real-time aerosol density determination utilizing a modified scanning mobility particle sizer-aerosol particle mass analyzer system, Aerosol Sci. Technol., 43, 673678, 2009.

Marley, N. A., Gaffney, J. S., Baird, J. C., Blazer, C. A., Drayton, P. J., and Frederick, J. E.: An empirical method for the determination of the complex refractive index of size-fractionated atmospheric aerosols for radiative transfer calculations, Aerosol Sci. Technol., 34, 535-549, 2001.

McMurr,y P. H., Wang, X., Park, K., and Ehara, K.: The relationship between mass and mobility for atmospheric particles: a new technique for measuring particle density, Aerosol Sci. Technol., 36, 227-238, 2002.

Nakajima, T., Tanaka, M., and Yamauchi, T.: Retrieval of the optical properties of aerosols from aureole and extinction data, Appl. Optics, 22, 2951-2959, 1983.

Nakajima, T., Tonna, G., Rao, R. Z., Boi, P., Kaufman, Y., and Holben, B.: Use of sky brightness measurements from ground for remote sensing of particulate polydispersions, Appl. Optics, 35, 2672-2686, 1996.

Nakayama, T., Sato, K., Matsumi, Y., Imamura, T., Yamazaki, A., and Uchiyama, A.: Wavelength dependence of refractive index of secondary organic aerosol generated during the ozonolysis and photooxidation of $\alpha$-pinene, Sola, 8, 119-123, 2012.

Nakayama, T., Sato, K., Matsumi, Y., Imamura, T., Yamazaki, A., and Uchiyama, A.: Wavelength and $\mathrm{NO}_{x}$ dependent complex refractive index of SOAs generated from the photooxidation of toluene, Atmos. Chem. Phys., 13, 531-545, https://doi.org/10.5194/acp-13-531-2013, 2013.

Nelder, J. A. and Mead, R.: A simplex method for function minimization, Comp. J., 7, 308-313, https://doi.org/10.1093/comjn1/7.4.308, 1965.

Nilsson, B.: Meteorological influence on aerosol extinction in the 0.2-40-mm wavelength range, Appl. Opt., 18, 3457-3473, 1979.

Palmer, K. F. and Williams, D.: Optical constants of sulfuric acid Application to clouds of Venus, Appl. Opt., 14, 208-219, 1975.

Patterson, E. M., Gillete, D. A., and Stockton, B. H.: Complex index of refraction between 300 and $700 \mathrm{~nm}$ for Saharan aerosol, J. Geophys. Res., 82, 3153-3160, 1977.

Raut, J.-C. and Chazette, P.: Retrieval of aerosol complex refractive index from a synergy between lidar, sunphotometer and in situ measurements during LISAIR experiment, Atmos. Chem. Phys., 7, 2797-2815, https://doi.org/10.5194/acp-7-2797-2007, 2007. 
Schuster, G. L., Dubovik, O., and Arola, A.: Remote sensing of soot carbon - Part 1: Distinguishing different absorbing aerosol species, Atmos. Chem. Phys., 16, 1565-1585, https://doi.org/10.5194/acp-16-1565-2016, 2016.

Senftleben, H. and Benedict, E.: Über die optischen Konstanten und die Strahlungsgesetze der Kohle, Annalen der Physik, 54, 65-78, 1917.

Sinyuk, A., Torres, O., and Dubovik, O.: Combined use of satellite and surface observations to infer the imaginary part of refractive index of Saharan dust, Geophys. Res. Lett., 30, 1081, https://doi.org/10.1029/2002GL016189, 2003.

Sokolik, I. N., and Toon, O. B.: Incorporation of mineralogical composition into models of the radiative properties of mineral aerosol from UV to IR wavelengths, J. Geophys. Res., 104, 9423-9444, 1999.

Volz, F. E.: Infrared optical constants of ammonium sulfate, Sahara dust, volcanic pumice, and fly ash, Appl. Opt., 12, 564-568, 1973.

Wagner, R., Ajtai, T., Kandler, K., Lieke, K., Linke, C., Müller, T., Schnaiter, M., and Vragel, M.: Complex refractive indices of Saharan dust samples at visible and near UV wavelengths: a laboratory study, Atmos. Chem. Phys., 12, 2491-2512, https://doi.org/10.5194/acp-12-2491-2012, 2012.

Wendisch, M. and von Hoyningen-Huene, W.: Possibility of refractvie index determination of atmospheric aerosol particles by ground-based solar extinction and scattering measurements, Atmos. Environ., 28, 785-792, 1994.

Willeke, K. and Whitby, K. T.: Atmospheric aerosols: size distribution interpretation, J. Air. Pollut. Contr. Assoc., 25, 529-534, 1975.
Woo, C., You, S., and Lee, J.: Determination of refractive index for absorbing spheres, Optik, 124, 5254-5258, 2013.

Wu, L., Hasekamp, O., van Diedenhoven, B., and Cairns, B.: Aerosol retrieval from multiangle, multispectral photopolarimetric measurements: importance of spectral range and angular resolution, Atmos. Meas. Tech., 8, 2625-2638, https://doi.org/10.5194/amt-8-2625-2015, 2015.

Xu, X., Wang, J., Zeng, J., Spurr, R., Liu, X., Dubovik, O., Li, L., Li, Z., Mishchenko, M. I., Siniuk, A., and Holben, B. N.: Retrieval of aerosol microphysical properties from AERONET photo-polarimetric measurements: 2. A new research algorithm and case demonstration, J. Geophys. Res.-Atmos., 120, 70797098, https://doi.org/10.1002/2015JD023113, 2015.

Zhang, R., Jing, J., Tao, J., Hsu, S.-C., Wang, G., Cao, J., Lee, C. S. L., Zhu, L., Chen, Z., Zhao, Y., and Shen, Z.: Chemical characterization and source apportionment of $\mathrm{PM}_{2.5}$ in Beijing: seasonal perspective, Atmos. Chem. Phys., 13, 7053-7074, https://doi.org/10.5194/acp-13-7053-2013, 2013.

Zhang, Y., Li, Z., Wang, Y., Li, K., Li, D., Zhang, Y. H., Wei, P., Wang, L., and Lv, Y.: Improving accumulation mode fraction based on spectral aerosol optical depth in Beijing, Spectroscopy and Spectral Analysis, 33, 2795-2802, 2013.

Zhang, Y.: CRIs of fine and coarse mode in Beijing, available at: https://www.researchgate.net/publication/319329141_CRIs_ of_fine_and_coarse_mode_in_Beijing, August 2017.

Zhu, C., Byrd, R. H., and Nocedal, J.: L-BFGS-B: Algorithm 778: L-BFGS-B, FORTRAN routines for large scale bound constrained optimization, ACM Transactions on Mathematical Software, 23, 550-560, 1997. 